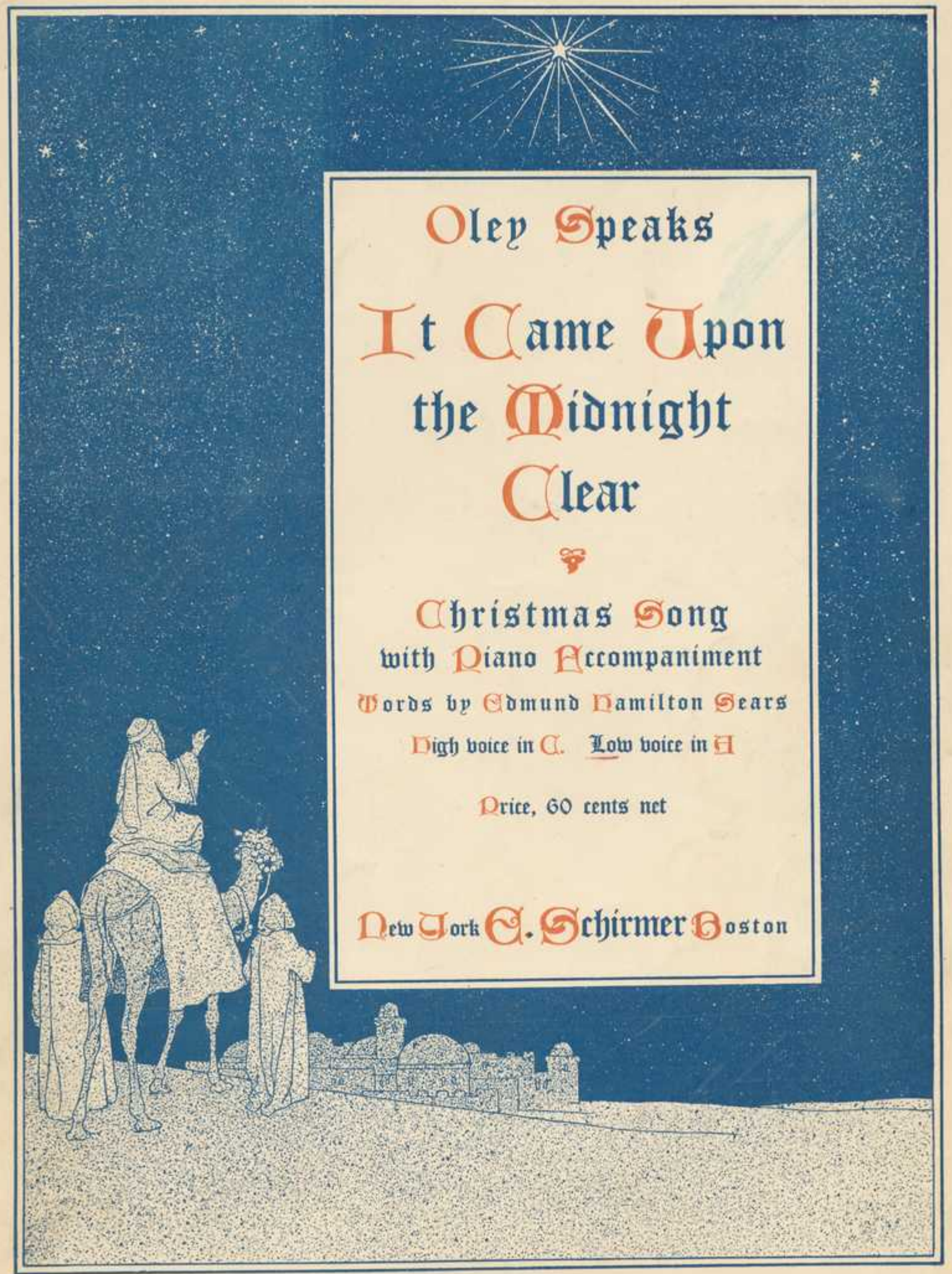


2

\section{It Came Upon the Midnight Clear}

Edmund Hamilton Sears

Oley Speaks

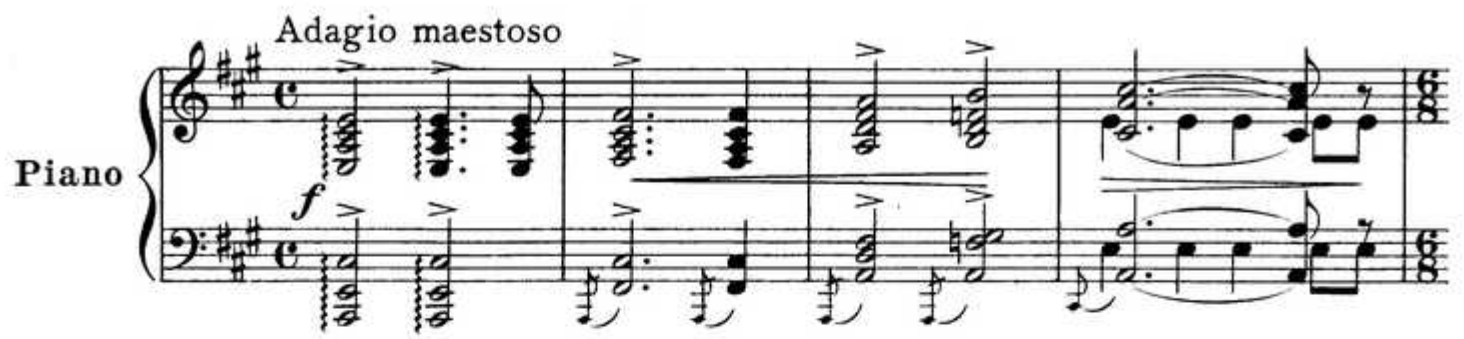

Allegretto
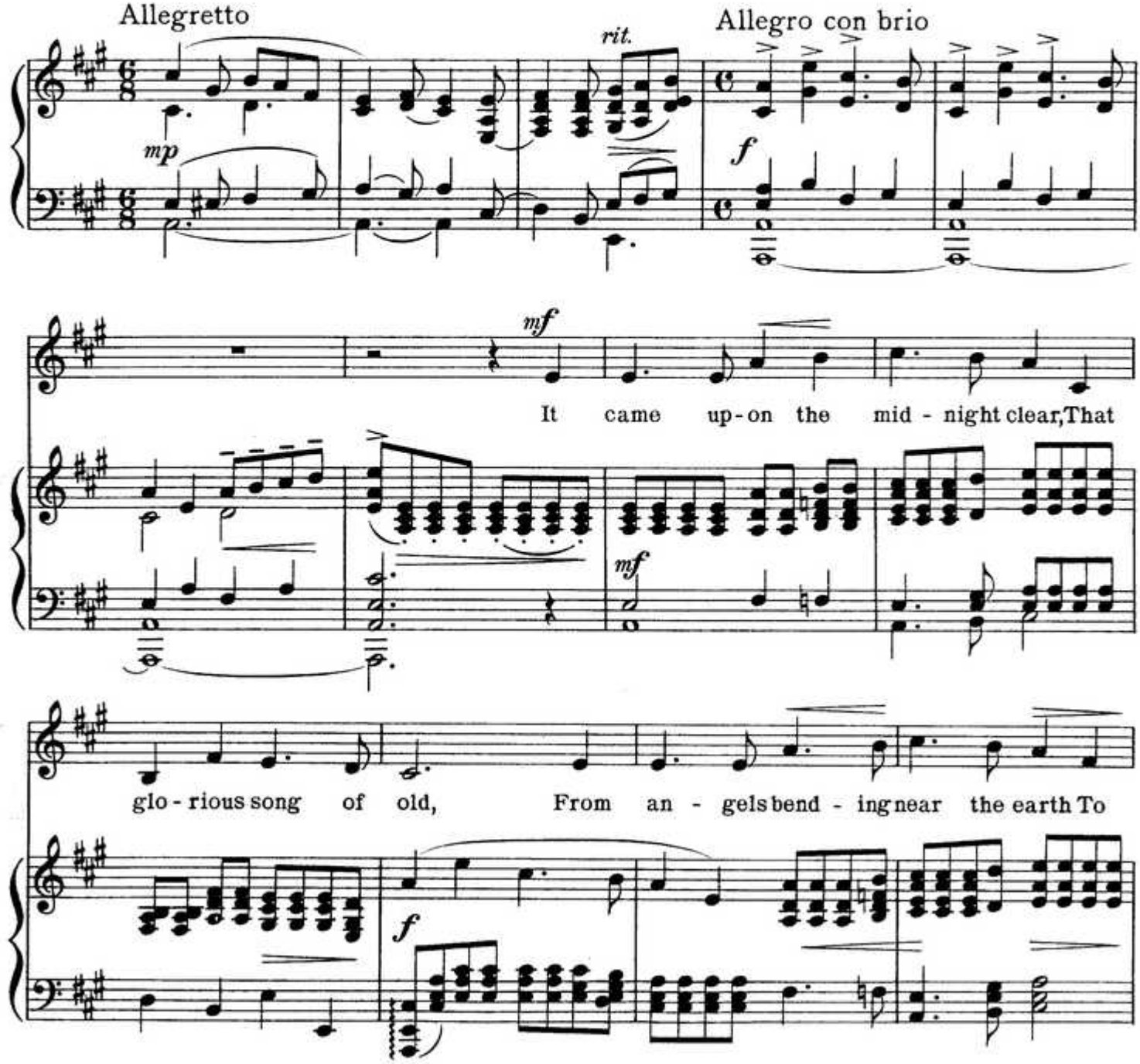


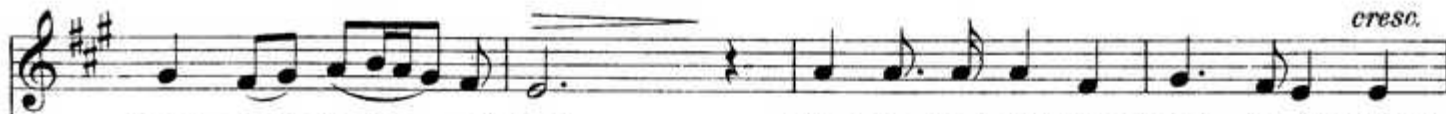
touch their harps_ of gold; Peace on the earth,good will to men, From

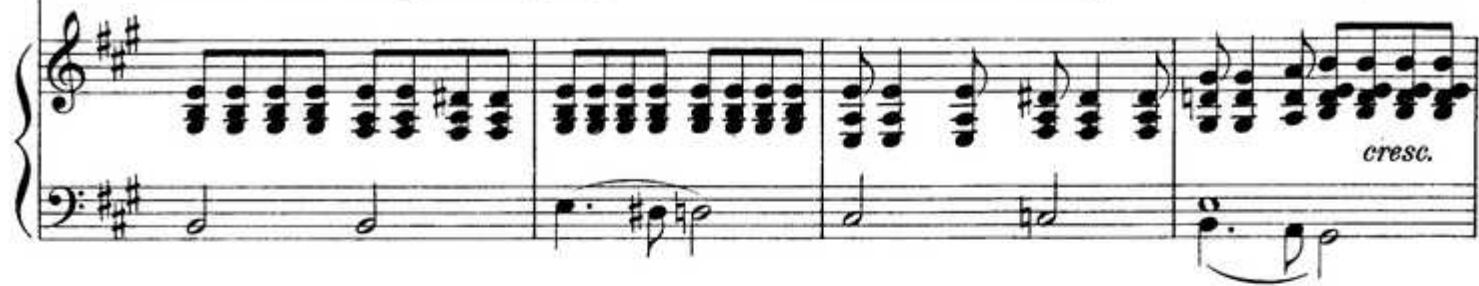

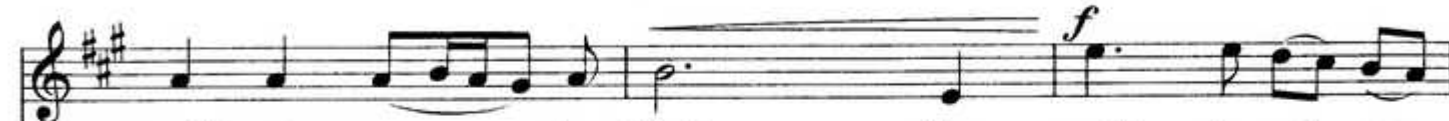
heav'n's all - gra - cious King! The world in sol - emn
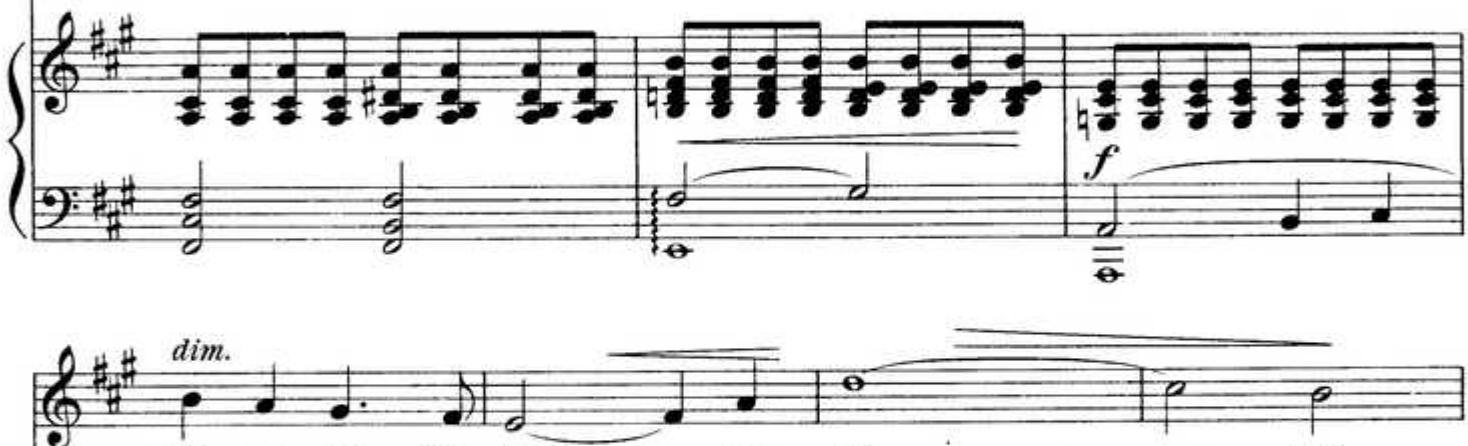
still-ness lay To hear__ the an - -
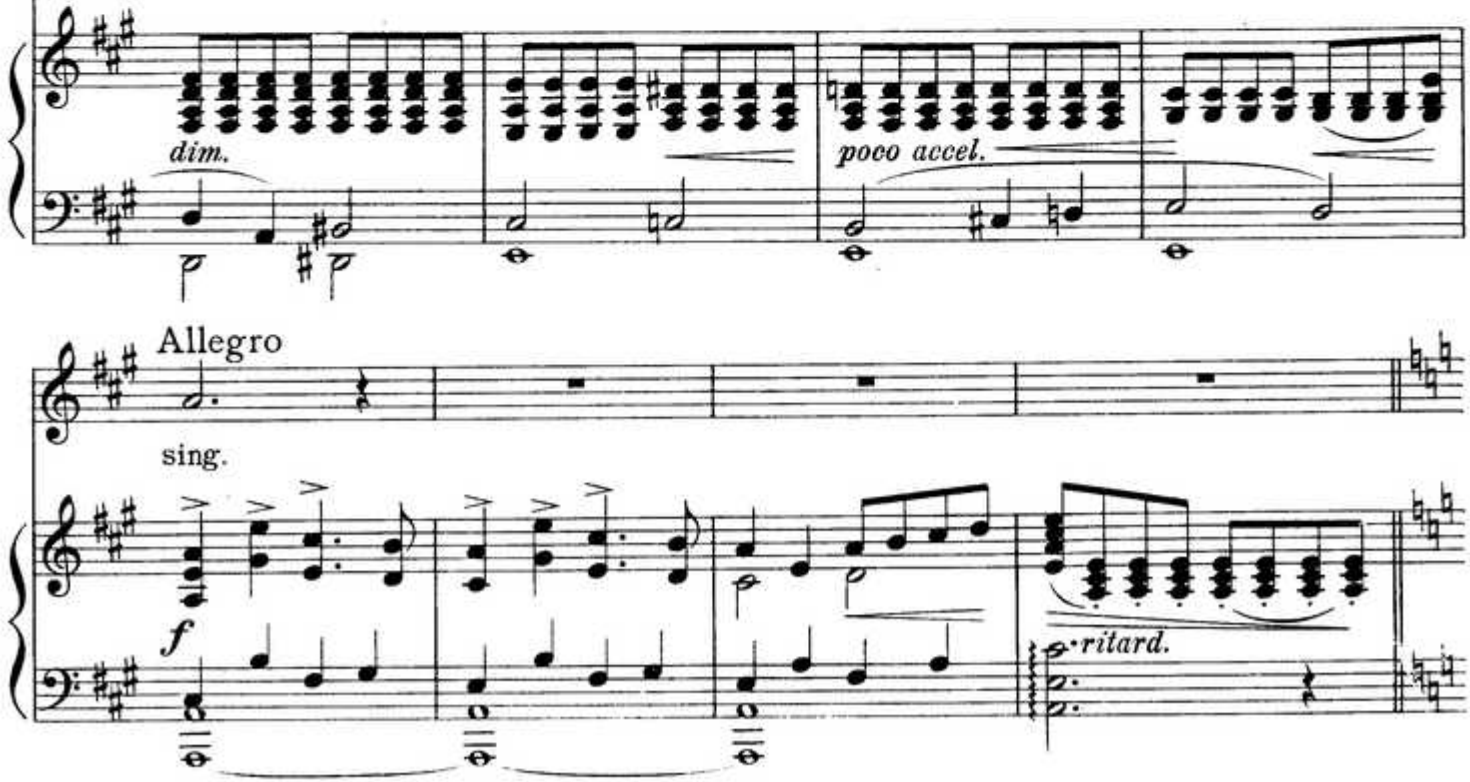

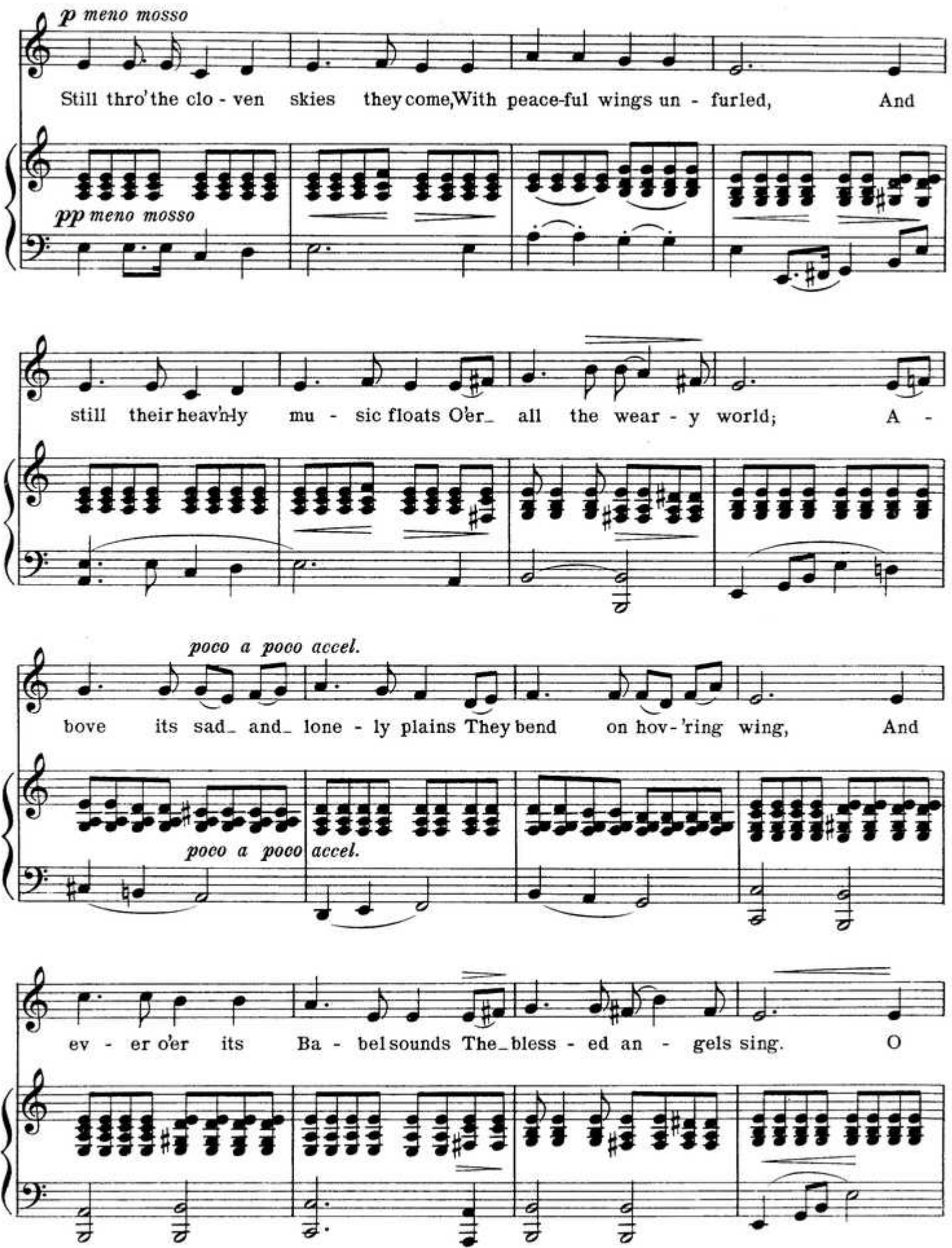

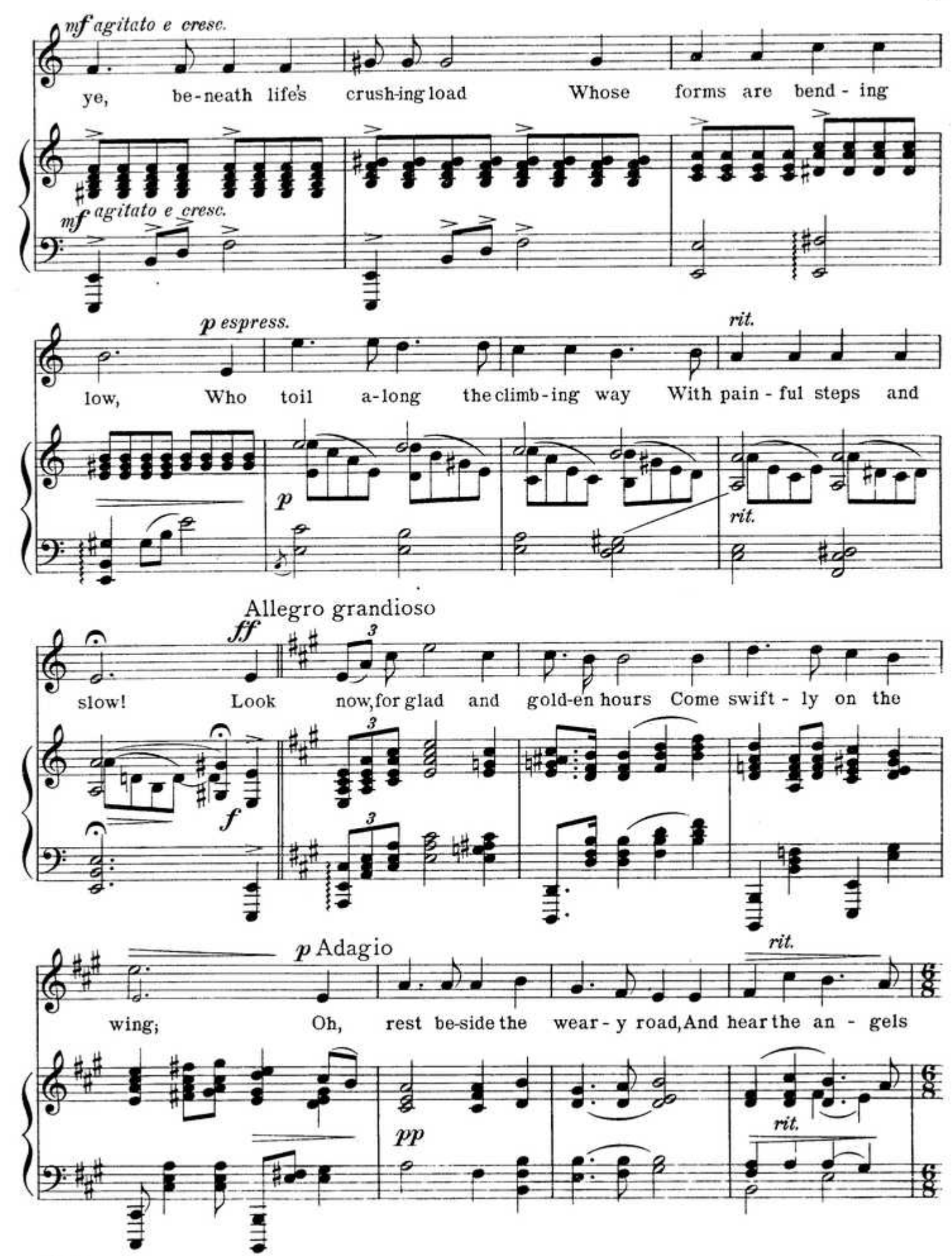

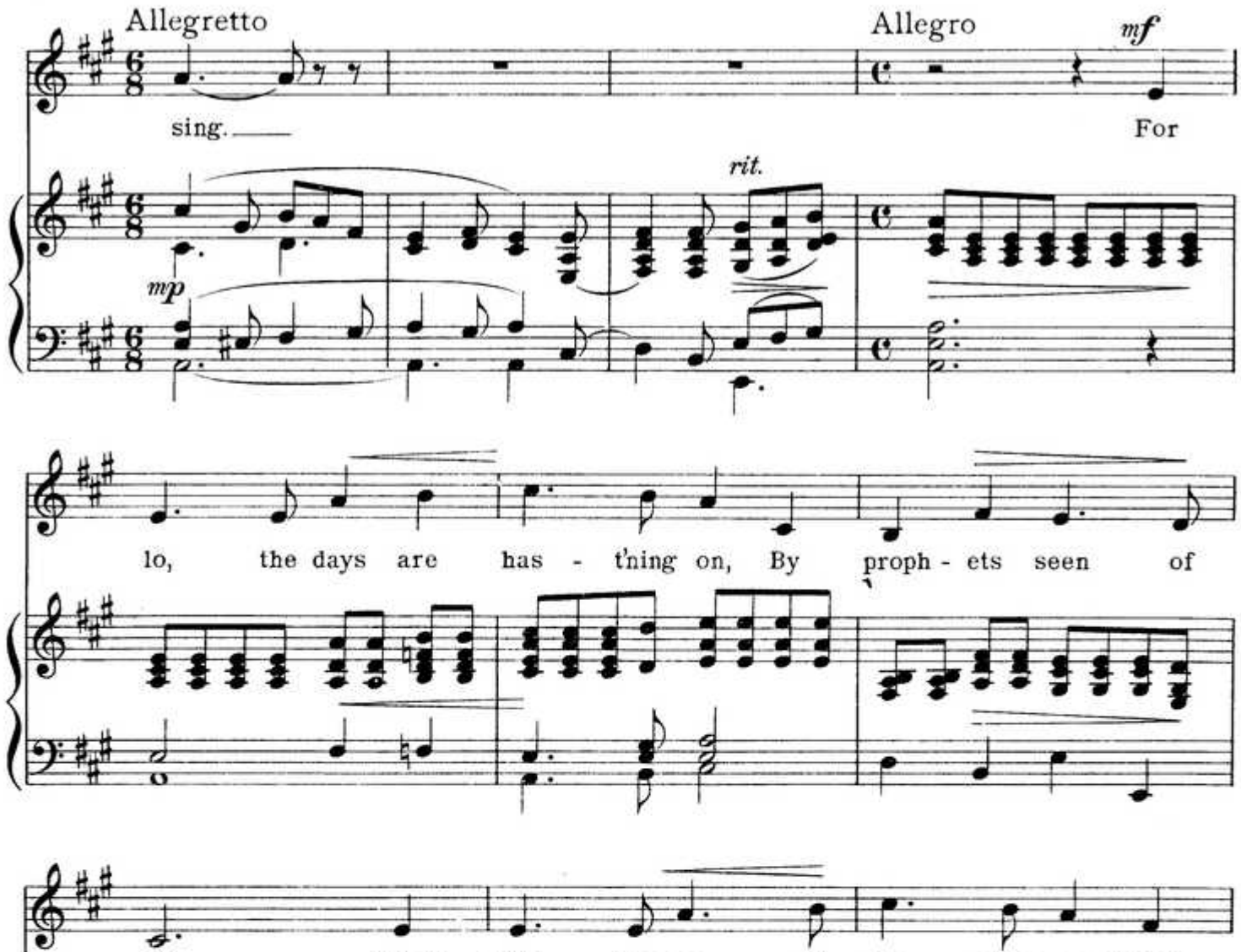
old, When with the ev - er - cir - cling years Shall
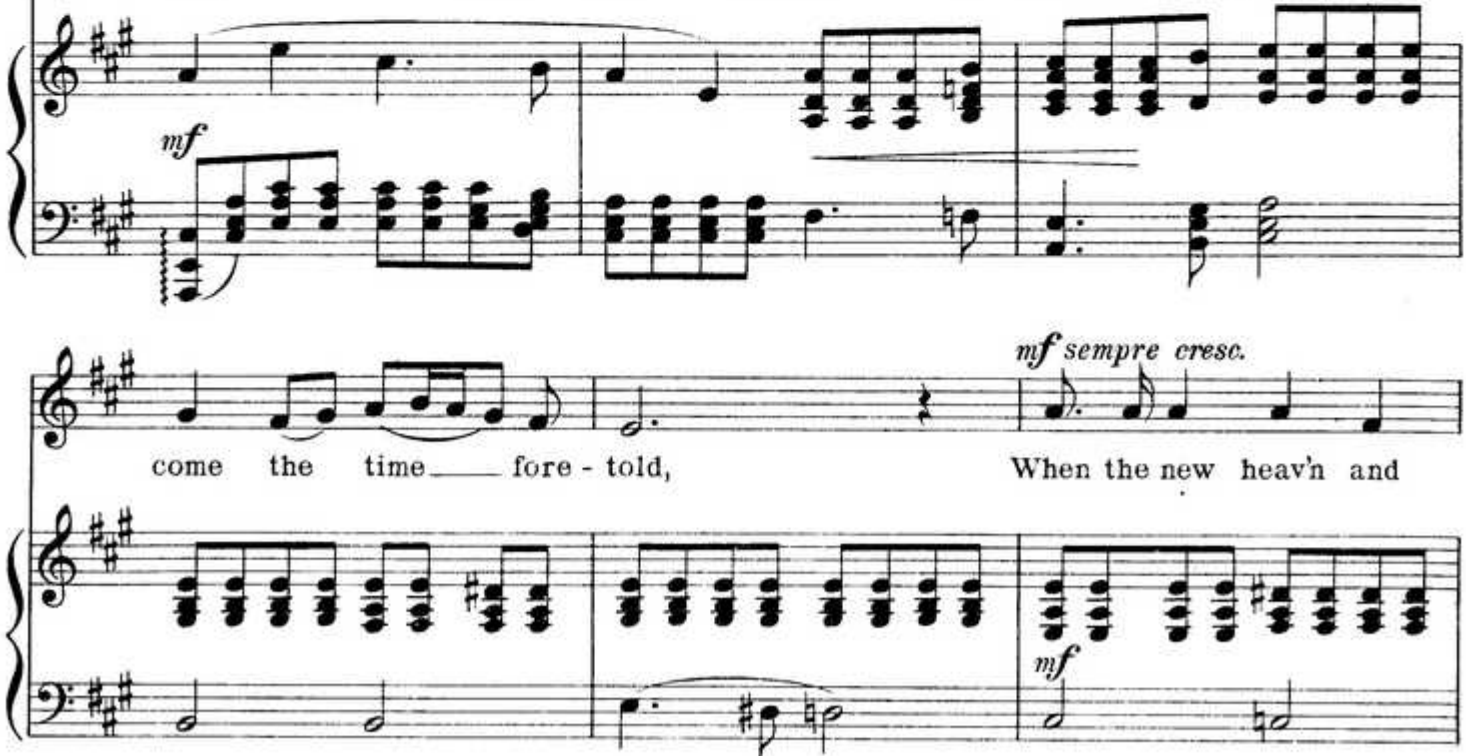

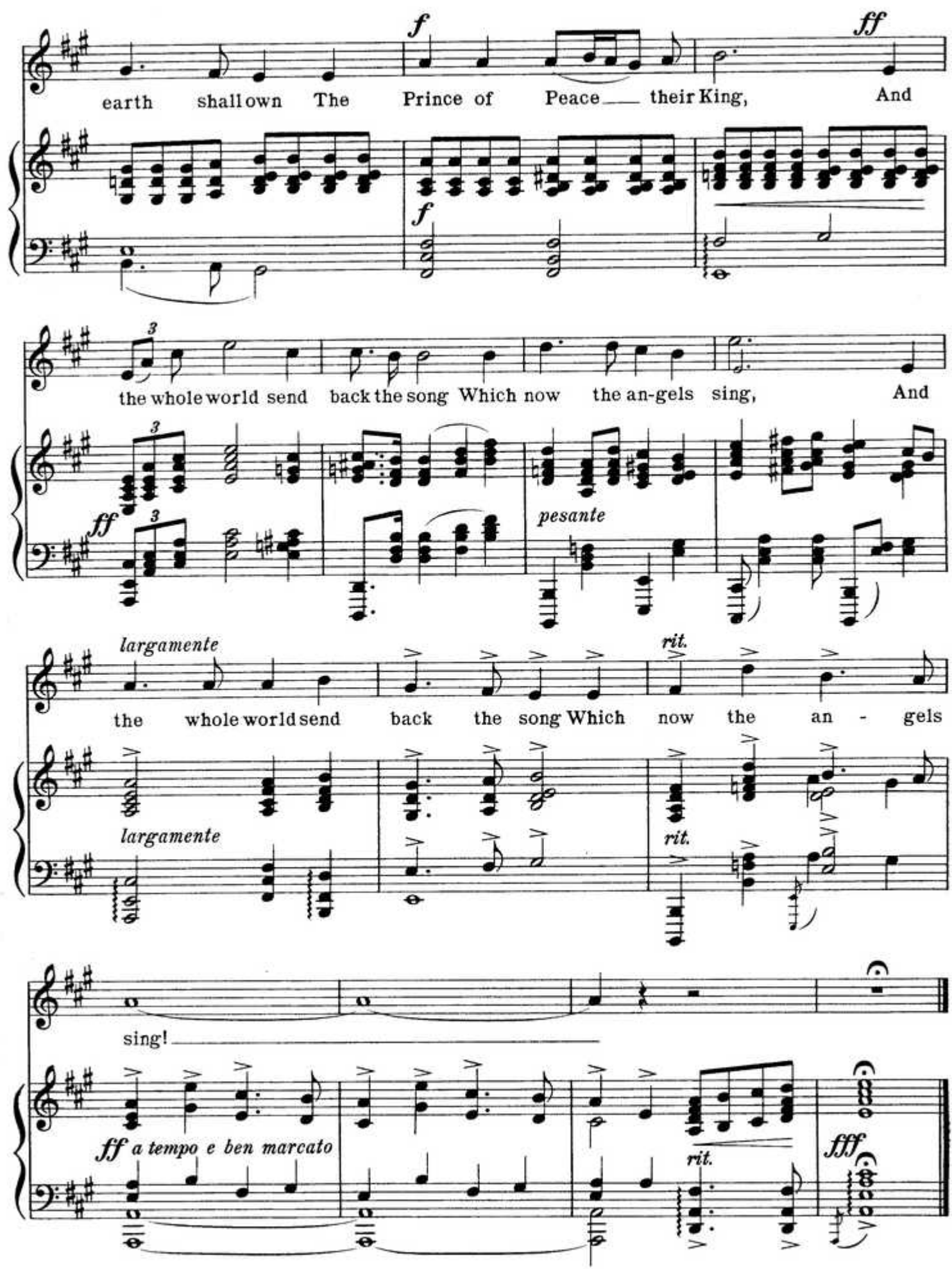


\section{Four New Sacred Songs}

\section{A Prayer}

Hotert Sewtieg

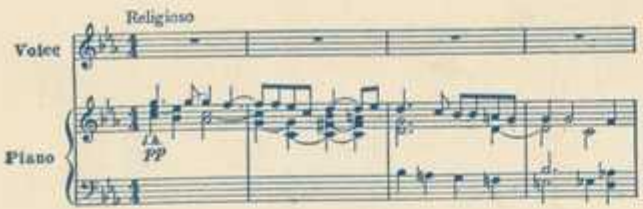

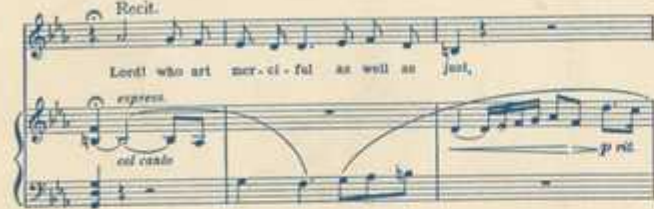

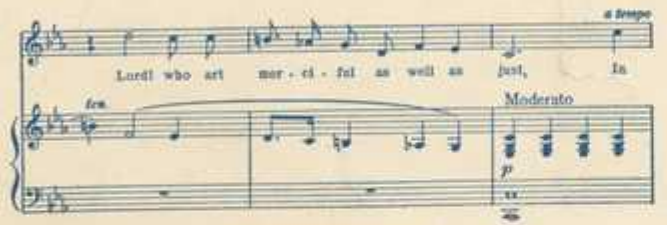

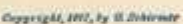

Price, 60 cents no

\section{Repent Ye}

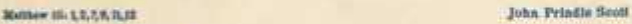

Votoe

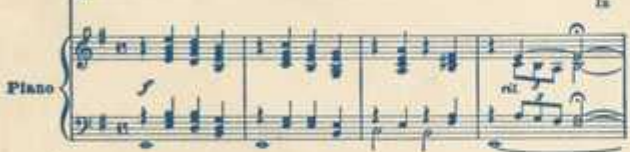

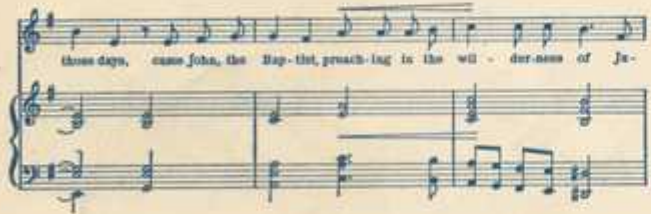

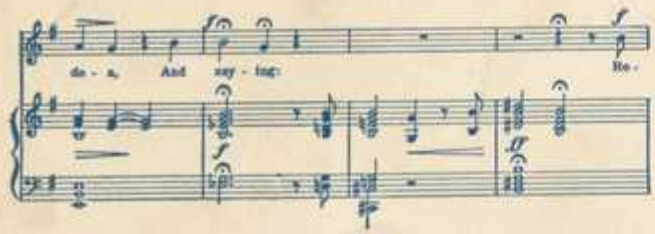

Coprest ust, hy a slumg

Price, 69 cents net o Master, let me walk with Thee

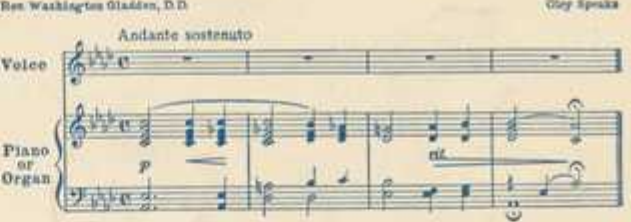

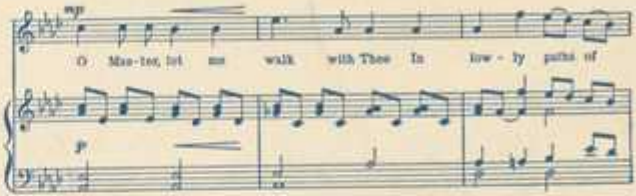

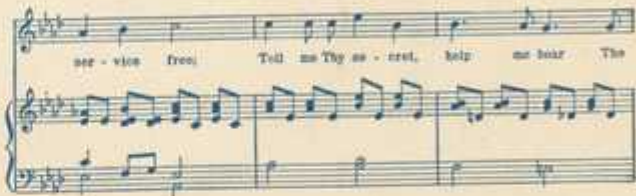

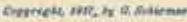

Price, 60 cents net

Come, Ye Blessed

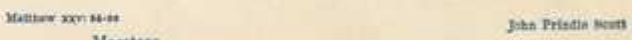
Valce 2 Mantoso

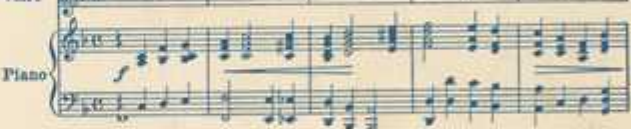
造:

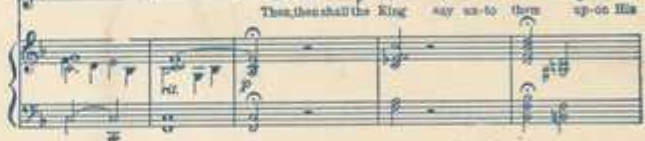

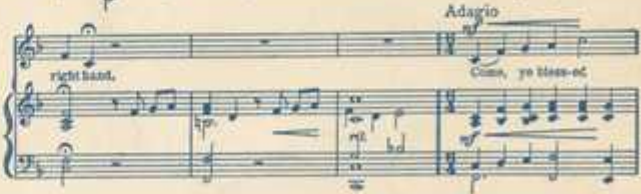

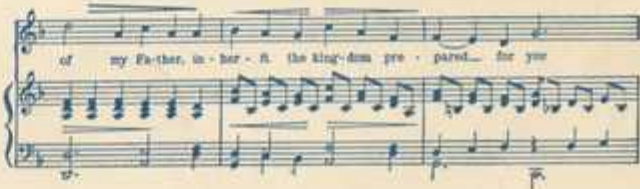

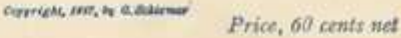

